\title{
BMJ Open Protocol for developing the evidence base for a national salt reduction programme for India
}

Claire Johnson, ${ }^{1,2}$ Sailesh Mohan, ${ }^{3}$ Deversetty Praveen, ${ }^{1,2}$ Mark Woodward, ${ }^{1,2}$
Pallab K Maulik, ${ }^{1}$ Roopa Shivashankar, ${ }^{3,4}$ Ritvik Amarchand, ${ }^{5}$ Jacqui Webster, ${ }^{1}$
Elizabeth Dunford, ${ }^{1}$ Sudhir Raj Thout, ${ }^{1}$ Graham MacGregor, ${ }^{6}$ Feng He, ${ }^{6}$
K Srinath Reddy, ${ }^{3}$ Anand Krishnan, ${ }^{5}$ Dorairaj Prabhakaran, ${ }^{3,4}$ Bruce Neal ${ }^{1,7,8}$

\section{ABSTRACT}

Mohan S, Praveen D, et al. Protocol for developing the evidence base for a national salt reduction programme for India. BMJ Open 2014;4: e006629. doi:10.1136/ bmjopen-2014-006629

- Prepublication history for this paper is available online. To view these files please visit the journal online (http://dx.doi.org/10.1136/ bmjopen-2014-006629).

Received 16 September 2014 Accepted 1 October 2014

CrossMark

For numbered affiliations see end of article.

Correspondence to Dr Dorairaj Prabhakaran; dprabhakaran@ccdcindia
Introduction: The scientific evidence base in support of salt reduction is strong but the data required to translate these insights into reduced population salt intake are mostly absent. The aim of this research project is to develop the evidence base required to formulate and implement a national salt reduction programme for India.

Methods and analysis: The research will comprise three components: a stakeholder analysis involving government, industry, consumers and civil society organisations; a population survey using an agestratified and sex-stratified random samples drawn from urban (slum and non-slum) and rural areas of North and South India; and a systematic quantitative evaluation of the nutritional components of processed and restaurant foods. The stakeholder interviews will be analysed using qualitative methods to summarise the main themes and define the broad range of factors influencing the food environment in India. The population survey will estimate the mean daily salt consumption through the collection of $24 \mathrm{~h}$ urine samples with concurrent dietary surveys identifying the main sources of dietary sodium/salt. The survey of foods will record the nutritional composition of the chief elements of food supply. The findings from this research will be synthesised and proposals for a national salt reduction strategy for India will be developed in collaboration with key stakeholders.

Ethics and dissemination: This study has been approved by the Human Research Ethics Committees of the University of Sydney and the Centre for Chronic Disease Control in New Delhi, and also by the Indian Health Ministry's Screening Committee. The project began fieldwork in February 2014 and will report the main results in 2016 . The findings will be targeted primarily at public health policymakers and advocates, but will be disseminated widely through other mechanisms including conference presentations and peer-reviewed publications, as well as to the participating communities.

\section{INTRODUCTION}

High blood pressure is responsible for about 170000 deaths in India each year. ${ }^{1}$ India currently has an estimated 140 million people living with hypertension, a figure which is projected to rise to 214 million by 2030. Habitual excess salt consumption ${ }^{2}$ is a main determinant of the disease burden ascribed to high blood pressure ${ }^{3}$ leading to many serious but avoidable complications, premature mortality and significant healthcare costs. ${ }^{4}$ In addition to the adverse effects of salt on blood pressure and vascular risk, a range of other serious health problems are also implicated including gastric cancer and osteoporosis. ${ }^{5}$ On the basis of the evidence linking salt, blood pressure and vascular risk, ${ }^{6}{ }_{7}$ the WHO recommends that all member states implement a salt reduction programme. A $30 \%$ lowering in the mean population salt intake by 2025 has been included as one of the targets of the ' 25 by 25' United Nations-WHO initiative for the control of non-communicable diseases. ${ }^{8}$

Underpinning these recommendations are a number of comprehensive, authoritative reviews pertaining to the adverse effects of excess salt and the likely positive impact of salt reduction. 5-11 $^{9}$ Some studies reporting on the health effects of salt and salt reduction have been inconclusive; ${ }^{12} 13$ however, there are various methodological problems with these studies as detailed by the Science Advisory of the American Heart Association. ${ }^{14}$ When the totality of the evidence is evaluated in an objective and systematic way, it is clear that most populations are eating salt far in excess of physiological requirements; many individuals suffer serious illnesses as a consequence, and there is a high likelihood that reduced salt intake would produce substantial health gains. ${ }^{5}$ 15-19 A series of modelling exercises have highlighted the likely cost-effectiveness of national salt reduction strategies, with data for India 
suggesting a cost of less than Rs.4400 (about US\$70) per disability-adjusted life year (DALY) averted, and great potential to prevent very large numbers of premature cardiovascular deaths. ${ }^{20}$

While the scientific evidence base providing the rationale for salt reduction is strong, the data required to translate those scientific insights into policy and reduced population salt intake are mostly absent. ${ }^{18}{ }^{21} \mathrm{~A}$ majority of countries (India included) do not have the required data and the insights needed to develop and implement salt reduction programmes tailored to national circumstances. ${ }^{22}{ }^{23}$ This research seeks to assemble the key baseline data needed to ensure that a coordinated salt reduction strategy can be delivered and thus achieve by 2025 the WHO target of a $30 \%$ reduction in dietary salt intake.

\section{METHODS AND ANALYSIS}

\section{Overall goal and specific objectives}

The overall goal of this 3-year project is to develop the knowledge base required to formulate a national salt reduction programme for India. This will be done by conducting an integrated, multifaceted research programme comprising stakeholder assessments, population surveys and food supply evaluations. It is hoped that this research will then provide the data required to formulate and implement a plausible national salt reduction programme for India (figure 1). The specific objectives for each research component are:

1. Stakeholder survey-to obtain a comprehensive understanding of consumer and other stakeholder opinions in relation to the most effective mechanisms for reducing salt intake.

2. Population survey-to estimate the mean daily salt consumption of the Indian population, the sources of variation about this mean, the main sources of salt in the diet and population knowledge about the adverse effects of salt on health.
3. Food survey-to estimate the mean and variation in the nutritional quality of common processed and restaurant foods.

Using the information collected in the above pieces of work, a comprehensive policy response and action plan will be developed for consideration by the Indian government. This is likely to include a range of interventions targeted at (1) stores, (2) street vendors, (3) chain restaurants, (4) food manufacturers and (5) consumers. Specific consideration will be given to the role of regulation.

\section{The stakeholder survey}

Inclusion criteria: The participants for the stakeholder survey will be recruited from the central and state governments and health departments; WHO representatives from the Indian Office and the South East Asia Regional Office; the Indian Council of Medical Research; the World Bank; the salt manufacturing industry; food manufacturers; academia; non-governmental organisations; developmental agencies and civil society. Additionally, community members from the population survey sites in urban, urban slum and rural areas will be invited to participate.

Recruitment: This will be done through existing contacts and networks using a purposive approach to sampling in an effort to secure representation from all key groups. Where the required contacts do not currently exist, they will be identified from desk research and an invitation will be made by a senior member of the research team based in India. In every case, participants will be contacted directly by telephone or email to seek their involvement. They will be provided with a participant information sheet, have any questions answered and be asked to sign a consent form before the study begins.

Data collection: This will comprise in-depth interviews and focus group discussions, done separately with each of the main participant groups, with each group

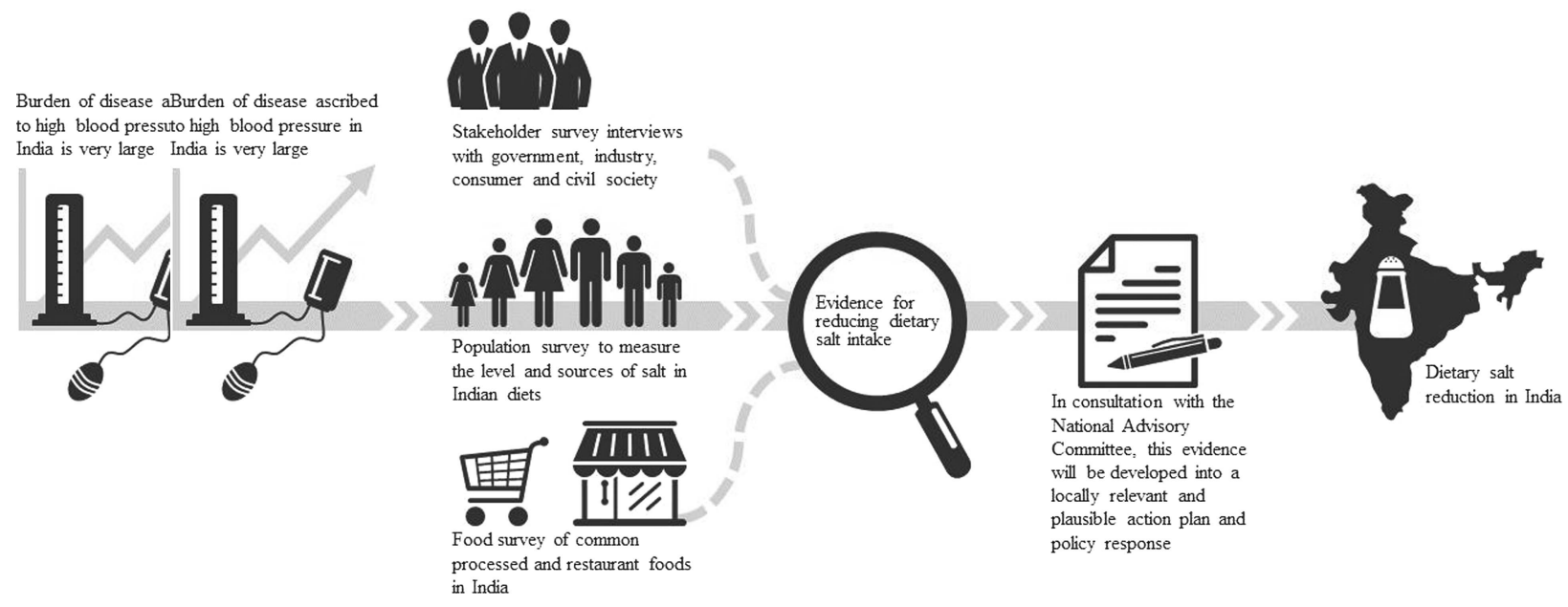

Figure 1 The research and development plan 1. 
facilitated by a professional researcher and anticipated to last between 1 and $2 \mathrm{~h}$. Interviews and discussions will be held at locations convenient to participants and will be audio recorded.

The primary outcome: Sought from the stakeholder survey will be a comprehensive understanding of the national landscape in regard to the potential for new food policy more broadly and for salt reduction in particular. The feasibility, barriers and opportunities will be identified such that the actions required to deliver a locally applicable and acceptable salt reduction strategy are understood.

Sample size and data analysis: About 50 in-depth interviews will be conducted and three focus groups, each involving 8-12 participants, will be held. The discussion from the focus groups and in-depth interviews will be transcribed, translated if required and analysed according to key themes using NVivo software. The findings will be provided back to the participants for review and comment prior to dissemination.

\section{The population survey}

The geographical sites: Sites have been selected to include slum and non-slum urban areas as well as rural communities. In North India, the urban part of the survey will be conducted in Delhi and the rural part in Faridabad, Haryana. In South India, the sites will be in Andhra Pradesh, with Hyderabad selected for the urban component and the West Godavari district for the rural component. In both cases, the areas for study have been selected on the basis of existing collaborations with the respective communities.

Recruitment of participants: This will be done using a stratified random sampling method to recruit individuals from urban, urban slum and rural areas into six age and sex groups. Before data collection begins, the Panchayat (local administrative body) will be engaged and permission to conduct the study in each area will be sought. In North India, census enumeration blocks (CEBs) and villages are sampled at random from within the study area. Households are then selected at random and an individual from within each household is selected at random until recruitment numbers in each stratum are fulfilled. In South India, the CEBs and villages are selected to be broadly representative of those in the State using a purposive process. A census list including information about the age and sex of all inhabitants is then compiled for each CEB and village, and a random sample of the population is invited to participate until recruitment numbers in each stratum are fulfilled. While the sampling processes are slightly different, the intent for North and South India is to recruit about equal numbers into each of the six strata defined by age and sex for each of the urban, urban slum and rural populations.

Data collection: This will occur during a pair of visits made within a week by a trained field researcher. The first action will be to provide the potential participant with the Participant Information Sheet and obtain consent. This will be done in the local language through a face-to-face invitation made at home. Consenting individuals will then be asked a series of questions about demographics; lifestyle behaviors; disease history; medication use; and knowledge, attitudes and practices related to salt. A $24 \mathrm{~h}$ dietary recall survey will be completed and measurements of height, weight, waist circumference and blood pressure will be made using established methods. ${ }^{24}$ Participants will be provided with the materials required to complete a $24 \mathrm{~h}$ and spot urine collection including a detailed instruction sheet. A day will be agreed on for the urine collection, and a second visit will be scheduled to collect the urine sample and complete a second $24 \mathrm{~h}$ dietary recall survey. Efforts will be made to collect diet recall data and urine samples on weekdays and weekends. Urine samples will be collected, the volume measured and an aliquot transferred to a central laboratory for analysis.

Outcomes: The primary outcome will be $24 \mathrm{~h}$ urinary sodium. Secondary outcomes will be $24 \mathrm{~h}$ urinary potassium, the ratio of sodium to potassium, knowledge levels, current practices relating to sodium and the main sources of sodium/salt in the diet.

Sample size and data analysis: A minimum of 1200 adults (600 from North India and 600 from South India) will be recruited in approximately equal numbers from urban, urban slum and rural areas (about 400 in each area). Recruitment will be further stratified to ensure that across the study there are about 200 individuals in each of six age $(20-39,40-59,60+)$ and sex strata. Assuming an SD of salt consumption of $4.5 \mathrm{~g} /$ day $^{25}$ and a mean intake of between 8 and $16 \mathrm{~g} /$ day, the study will estimate the mean level of salt consumption to within $\pm 0.3 \mathrm{~g} /$ day with $95 \%$ CI. For subgroups of men versus women, urban versus rural and older versus younger individuals, it will be possible to estimate mean levels of salt consumption to within $\pm 0.7 \mathrm{~g}$ /day and to detect differences in consumption between subgroups of $1.2 \mathrm{~g} /$ day or greater. If the survey were to be repeated in a few years, there would be $90 \%$ power $(\alpha=0.05)$ to detect $0.5 \mathrm{~g} /$ day or greater differences in average salt consumption levels between the surveys.

Urinary sodium, potassium and creatinine will be determined using the ion selective electrode method for sodium and potassium analysis and the buffered kinetic Jaffe reaction without deproteinisation for the urine creatinine assay. Overall population estimates will be made by weighting the age-specific and sex-specific estimates obtained from the survey using population weights calculated from census data. The results will also be reported for major participant subgroups defined by sex, age and area of residence with evidence for differences between subgroups tested. Estimates of sodium consumption will also be made directly from the dietary survey data and compared with those obtained from the $24 \mathrm{~h}$ urine samples. 


\section{Surveys of packaged and restaurant foods}

The dietary intake data collected during the population survey will provide direct quantitative insight into the foods consumed by the population. To determine the contribution of salt from each food source requires additional information about the composition of the foods eaten. For fresh products, this can be obtained from food composition tables, ${ }^{26}$ and there are also some existing data about the composition of recipes for foods eaten at home or at traditional street hawker-type food service outlets. ${ }^{27}$ However, for packaged foods and chain restaurant products, there are no databases that systematically record the composition of the many different items now available.

Retail outlets to be surveyed: Using information gleaned from the stakeholder analysis and the dietary survey, supplemented by desk research, the range of sales outlets from which the population obtains packaged foods and chain restaurant foods will be identified. These outlets are anticipated to include large supermarkets, smaller shops and corner stores as well as a range of local and international chain restaurants.

Food products to be included: For each outlet identified, systematic surveys will be conducted to document the range of products sold and the salt content of each item (table 1). This will be done using Internet searches (mainly to seek data about chain restaurants) and by undertaking in-store surveys of food packaging (mainly to seek data about packaged foods). Where data are not available for larger corporations, we will make written requests in an attempt to access the data. The survey processes will be based on those previously detailed. ${ }^{28} 29$

Process for in-store data collection: Permission to collect data from larger stores will be sought by letter, email or telephone to head offices while smaller stores will be visited in person. Once permission is obtained, data collection comprises the systematic recording of every packaged food item in the store using a smartphone application to record the barcode and take photographs of the front of the pack, the nutrition information panel and the ingredients list. The photos are uploaded to a central database and the data (table 2) are entered and the products categorised into about 600 different subgroups. For fast-food chains, in-store nutrition data will be sought from pamphlets, tray liners, food packaging or other sources, as might be available.

Outcomes: This will be the proportion of products with nutritional information about sodium provided in line with established government and international recommendations, and the levels of sodium in products. The levels of other nutrients will also be recorded and reported where they are available. The collated information will be compiled with that from existing food composition databases to enable a robust evaluation of the dietary survey data.

Data analysis: The analysis will focus on the separate levels of sodium in packaged and chain restaurant foods, both overall and according to major food categories, and for leading manufacturers and retailers. The sample size cannot be fixed in advance because there are few data available to describe the number of processed or restaurant foods for sale or the availability of nutritional information.

\section{Formulation of a national salt reduction strategy}

The information collected during the stakeholder consultations, population surveys and evaluations of the food supply will be used to develop a comprehensive understanding of potential mechanisms for reducing dietary sodium/salt in India. These insights will be developed into an action plan and policy response. This will be done in consultation with a National Advisory Committee which includes a diverse range of members from national government organisations, multilateral health agencies, the civil society and research organisations. Consideration will be given to stakeholder and consumer opinions and key social and cultural factors, including geographical diversity, as well as evidence of effectiveness of different approaches to salt reduction around the world. The goal is to develop a locally

\begin{tabular}{|c|c|}
\hline Data field & Variable \\
\hline Demographics & $\begin{array}{l}\text { Age, years } \\
\text { Sex } \\
\text { Religion } \\
\text { Education } \\
\text { Number of people in household } \\
\text { Employment status } \\
\text { Household income }\end{array}$ \\
\hline Self-assessed health & $0-100$ (0=worst, $100=$ best $)$ \\
\hline Tobacco use & Current/ever \\
\hline Drinking & $\begin{array}{l}1 \text { week or less, }>1 \text { week } \\
<12 \text { months, }>12 \text { months, never }\end{array}$ \\
\hline Physical activity & $\begin{array}{l}\text { Vigorous, moderate or walking in } \\
\text { a usual } 7 \text { days }\end{array}$ \\
\hline Disease history & $\begin{array}{l}\text { High blood pressure } \\
\text { Low blood pressure } \\
\text { High cholesterol } \\
\text { Heart attack } \\
\text { Stroke } \\
\text { Angina } \\
\text { Diabetes } \\
\text { Chronic kidney disease }\end{array}$ \\
\hline $\begin{array}{l}\text { Prescription } \\
\text { medication }\end{array}$ & $\begin{array}{l}\text { Antihypertensive } \\
\text { Lipid lowering } \\
\text { Aspirin } \\
\text { Glucose lowering }\end{array}$ \\
\hline $\begin{array}{l}\text { Physical } \\
\text { measurements }\end{array}$ & $\begin{array}{l}\text { Height } \\
\text { Weight } \\
\text { Waist circumference } \\
\text { Blood pressure }\end{array}$ \\
\hline $\begin{array}{l}\text { Knowledge, attitudes } \\
\text { and behaviours } \\
24 \mathrm{~h} \text { dietary recall }\end{array}$ & $\begin{array}{l}\text { Dietary habits, use of salt in } \\
\text { cooking, control of salt intake, etc } \\
\text { Multiple pass method }\end{array}$ \\
\hline
\end{tabular}


Table 2 Main data items collected for the food composition survey

\begin{tabular}{ll}
\hline Variable & Format \\
\hline Product name & As per product label \\
Brand name & As per product label \\
Serves per pack & As per product label \\
Serving size & $\mathrm{g}$ or $\mathrm{mL}$ \\
Energy & $\mathrm{kJ}$ or kcal $/ 100 \mathrm{~g} \mathrm{or} 100 \mathrm{~mL}$ \\
Protein & $\mathrm{g} / 100 \mathrm{~g}$ or $100 \mathrm{~mL}$ \\
Fat, total & $\mathrm{g} / 100 \mathrm{~g}$ or $100 \mathrm{~mL}$ \\
$\quad$ Saturated fat & $\mathrm{g} / 100 \mathrm{~g}$ or $100 \mathrm{~mL}$ \\
Trans fat & $\mathrm{g} / 100 \mathrm{~g}$ or $100 \mathrm{~mL}$ \\
$\quad$ Polyunsaturated fat & $\mathrm{g} / 100 \mathrm{~g}$ or $100 \mathrm{~mL}$ \\
$\quad$ Monounsaturated fat & $\mathrm{g} / 100 \mathrm{~g}$ or $100 \mathrm{~mL}$ \\
Carbohydrate & $\mathrm{g} / 100 \mathrm{~g}$ or $100 \mathrm{~mL}$ \\
$\quad$ Sugars & $\mathrm{g} / 100 \mathrm{~g}$ or $100 \mathrm{~mL}$ \\
Fibre & $\mathrm{g} / 100 \mathrm{~g}$ or $100 \mathrm{~mL}$ \\
Sodium & $\mathrm{mg} / 100 \mathrm{~g}$ or $100 \mathrm{~mL}$ \\
Calcium & $\mathrm{g} / 100 \mathrm{~g}$ or $100 \mathrm{~mL}$ \\
Gluten & $\mathrm{g} / 100 \mathrm{~g}$ or $100 \mathrm{~mL}$ \\
Contains/may contain & As per the product label \\
Symbols and health & Health or nutrient claims or \\
claims & symbols* \\
\hline *Includes vegetarian or non-vegetarian status. \\
Data can also be entered as salt in g/100 g or $100 \mathrm{~mL}$. \\
\end{tabular}

relevant national salt reduction programme using existing frameworks for the development of salt reduction strategies. ${ }^{30}{ }^{31}$ It is anticipated that the strategy will have three main elements: working with the food industry to reformulate processed foods as well as meals provided at chain restaurants and smaller hawker-type outlets; sustained, locally relevant public education campaigns to change consumer behaviour; and efforts to change the food environment through the establishment of standards and educational programmes and by working in settings such as schools, hospitals and workplaces. As far as possible, the different elements of the strategy will be integrated into existing government and stakeholder programmes and activities.

\section{Ethics and dissemination}

The project began fieldwork in February 2014 and will report the main results in 2016. The findings will be targeted primarily at public health policymakers and advocates, but will be disseminated widely through other mechanisms including conference presentations and peer-reviewed publications, as well as to the participating communities.

\section{CURRENT STATUS}

Key stakeholders have been identified and initial email contact has been made with 61 potential participants. Follow-up is ongoing with the goal of completing the interviews and focus groups in 2014. The population survey has started in North and South India and is also anticipated to be completed in all sites by the end of
2014. Photographs have been collected for about 7500 products from 10 retail outlets in Hyderabad and Delhi.

\section{DISCUSSION}

India has relatively well organised strategies for prevention of non-communicable disease and has already highlighted salt reduction as a priority. ${ }^{32}$ As such, the time is ripe for a programme of work that can define the path towards policy actions targeting salt reduction. An effective Indian salt reduction programme would be anticipated to avert very large numbers of heart attack, stroke and other blood pressure-related diseases. ${ }^{33}$ With cardiovascular diseases already the leading cause of death in most parts of India, ${ }^{1}$ and cardiovascular disease events occurring on average a decade earlier than in the West, ${ }^{34}$ the potential significance of salt reduction for the health of the population is enormous. ${ }^{22} 23$

Several successful interventions to reduce dietary salt intake have demonstrated effectiveness in high-income countries. A salt reduction programme led by the Food Standards Agency and CASH (Consensus Action on Salt and Health) was launched in the UK in 2003, and it has since reduced dietary salt intake to 8.1 from $9.5 \mathrm{~g} /$ day as measured by $24 \mathrm{~h}$ urinary sodium excretion in a random sample of the population. ${ }^{35}{ }^{36}$ This reduction in salt intake was accompanied by a significant fall in the population's blood pressure and mortality from stroke and ischaemic heart disease. ${ }^{36}$ The success of the UK programme is largely due to establishing progressively lower targets for salt levels in foods. Japan and Finland also implemented successful salt reduction strategies in the 1970s and have reported reductions in daily salt intake of 2.3 and $4.7 \mathrm{~g}$ /day, respectively, driven by public education programmes (Japan), food reformulation targets and mandatory warning labels for foods high in salt (Finland). ${ }^{33}$ An important new approach is now being taken by South Africa, which has recently passed legislation making salt reduction in processed food mandatory, with initial reductions to be achieved by 2016, and further reductions enforced by $2018 .^{38}$ These and other completed and ongoing programmes, in conjunction with the collection of the new data described above, will support the development of the programme for India.

The key strengths of the current project are the new scientific data that will emanate from the large population surveys and the evaluations of the food supply. These will be important new data for India and will underpin the case for action. By conducting this survey work in conjunction with a stakeholder evaluation, there will be comprehensive information available for the development of practical strategies which should greatly increase the likelihood that the study outcome will translate into action. The study also benefits from the use of the best current method of quantification of dietary sodium intake based on $24 \mathrm{~h}$ urine collection.

The study also has some limitations. The population survey has been restricted to two states in India and has 
a relatively small sample size because of logistical and budgetary constraints. It will not provide definitive data about salt consumption patterns across the entirety of India but is not dissimilar in design to the annual National Nutrition Monitoring Bureau survey conducted by the National Institute of Nutrition ${ }^{39}$ - that survey is a very well-respected source of data on the nutritional status of the Indian population. The purposive nature of aspects of the sampling strategy have been used to ensure that, despite the relatively small sample size, broadly representative data are obtained from urban areas of different levels of affluence as well as rural areas. This is an approach that has been used in national surveys conducted in other countries ${ }^{40}$ to make inferences about national levels of risks, and is a reasonable pragmatic compromise. The food composition surveys will likewise initially be focused on a relatively small sample of packaged and restaurant foods in the study areas in North and South India. Further expansion of that aspect of data collection may be required before the scale-up and roll-out of a national salt reduction strategy can be done.

In conclusion, this study will generate substantive new data and should clearly define the potential for salt reduction in India. The findings will be targeted primarily at policymakers and activists, but will be disseminated widely through other mechanisms including conference presentations and peer-reviewed publications, as well as to the participating communities.

\author{
Author affiliations \\ ${ }^{1}$ George Institute for Global Health, Oxford University, Oxford, UK \\ ${ }^{2}$ University of Sydney, Sydney, Australia \\ ${ }^{3}$ Public Health Foundation of India, New Delhi, India \\ ${ }^{4}$ Centre for Chronic Disease Control, Gurgaon, India \\ ${ }^{5}$ All India Institute of Medical Science, New Delhi, India \\ ${ }^{6}$ Wolfson Institute of Preventative Medicine, London, UK \\ ${ }^{7}$ Royal Prince Alfred Hospital, Sydney, NSW, Australia \\ ${ }^{8}$ Imperial College London, London, UK
}

Contributors CJ wrote the first draft of this paper which BN updated for important content. SM, DeP, PKM, JW, GM, FH, KSR, AK and DoP contributed to the conception and design of the protocol; RS, RA, TSR and ED assisted with acquisition of data and MW contributed to the analysis and interpretation of the plan. All authors reviewed and provided written comments on subsequent iterations and also contributed to the design of the study.

Funding This work was supported by a funding award made by the Global Alliance for Chronic Disease through the National Health and Medical Research Council of Australia (grant number APP1040179).

Competing interests BN is the Chair of the Australian Division of World Action on Salt and Health. He receives funding support from the Australian Food and Grocery Council through a National Health and Medical Research Council of Australia Partnership Project grant and was a member of the Pepsico Global Scientific Advisory Board between 2011 and 2012. He is supported by an Australian Research Council Future Fellowship and a National Health and Medical Research Council of Australia Senior Research Fellowship. He also holds an NHMRC Program Grant. JW is the Director of the WHO Collaborating Centre on Population Salt Reduction at the George Institute. PKM is an Intermediate Career Fellow of the WT/DBT India Alliance.

Ethics approval Human Research Ethics Committees of the University of Sydney and the Centre for Chronic Disease Control in New Delhi, and also by the Indian Health Ministry's Screening Committee.
Provenance and peer review Not commissioned; internally peer reviewed.

Open Access This is an Open Access article distributed in accordance with the Creative Commons Attribution Non Commercial (CC BY-NC 4.0) license, which permits others to distribute, remix, adapt, build upon this work noncommercially, and license their derivative works on different terms, provided the original work is properly cited and the use is non-commercial. See: http:// creativecommons.org/licenses/by-nc/4.0/

\section{REFERENCES}

1. WHO. The world health report 2002: reducing risks, promoting healthy life. World Health Organization, 2002.

2. [No authors listed]. Intersalt: an international study of electrolyte excretion and blood pressure: result for 24 hour urinary salt and potassium excretion. Intersalt Cooperative Research Group. BMJ 1988;297:319-28.

3. Asaria P, Chisholm D, Mathers $C$, et al. Chronic disease prevention: health effects and financial costs of strategies to reduce salt intake and control tobacco use. Lancet 2007;370:2044-53.

4. Srinath Reddy K, Shah B, Varghese C, et al. Responding to the threat of chronic diseases in India. Lancet 2005;366:1744-9.

5. WHO. Reducing salt intake in populations: report of a WHO forum and technical meeting, 5-7 October 2006, Paris, France, 2007.

6. Cook NR, Cutler JA, Obarzanek E, et al. Long term effects of dietary sodium reduction on cardiovascular disease outcomes: observational follow-up of the trials of hypertension prevention (TOHP). BMJ 2007;334:885-8.

7. He F, MacGregor G. Effect of modest salt reduction on blood pressure: a meta-analysis of randomized trials. Implications for public health. J Hum Hypertens 2002;16:761-70.

8. WHO. Draft comprehensive global monitoring framework and targets for the prevention and control of noncommunicable diseases. 2013.

9. Campbell N, Neal B, MacGregor G. Interested in developing a national programme to reduce dietary salt? J Hum Hypertens 2011;25:705-10.

10. WHO. Global strategy on diet, physical activity and health: a framework to monitor and evaluate implementation, 2006.

11. Yang Q, Liu T, Kuklina EV, et al. Sodium and potassium intake and mortality among US adults: prospective data from the Third National Health and Nutrition Examination Survey. Arch Intern Med 2011;171:1183-91.

12. Stolarz-Skrzypek K, Kuznetsova T, Thijs L, et al. Fatal and nonfatal outcomes, incidence of hypertension, and blood pressure changes in relation to urinary sodium excretion. JAMA 2011;305:1777-85.

13. Taylor RS, Ashton KE, Moxham T, et al. Reduced dietary salt for the prevention of cardiovascular disease. Cochrane Database Syst Rev 2011;7:CD009217.

14. Cobb LK, Anderson CA, Elliott $P$, et al. Methodological issues in cohort studies that relate sodium intake to cardiovascular disease outcomes: a science advisory from the American Heart Association. Circulation 2014;129:1173-86.

15. Appel LJ, Frohlich ED, Hall JE, et al. The importance of population-wide sodium reduction as a means to prevent cardiovascular disease and stroke: a call to action from the American Heart Association. Circulation 2011;123:1138-43.

16. Campbell NR, Legowski B, Legetic B. Mobilising the Americas for dietary salt reduction. Lancet 2011;377:793-5.

17. Institute of Medicine (US). Panel on Dietary Reference Intakes for Electrolytes, and Water. DRI, dietary reference intakes for water, potassium, sodium, chloride, and sulfate. National Academy Press, 2005

18. He FJ, MacGregor GA. Reducing population salt intake worldwide: from evidence to implementation. Prog Cardiovasc Dis 2010;52:363-82.

19. Scientific Advisory Committee on Nutrition. Salt and Health. Norwich, UK, 2003:1e134.

20. Patel V, Chatterji S, Chisholm D, et al. Chronic diseases and injuries in India. Lancet 2011;377:413-28.

21. Neal BC. Don't spare the salt? An unsavoury tale of public health procrastination. Med J Aust 2011;195:111.

22. Mir MA, Mir F, Khosla T, et al. The relationship of salt intake and arterial blood pressure in salted-tea drinking Kashmiris. Int $J$ Cardiol 1986;13:279-88.

23. Goel N, Kaur P. Dr. PC Sen Memorial Award-1994. Role of various risk factors in the epidemiology of hypertension in a rural community of Varanasi district. Indian J Public Health 1995;40:71-6.

24. WHO. WHO STEPS stroke manual: the WHO STEPwise approach to stroke surveillance/Noncommunicable Diseases and Mental Health. World Health Organization, 2005.

25. Bernstein AM, Willett WC. Trends in 24-h urinary sodium excretion in the United States, 1957-2003: a systematic review. Indian J Public Health 2010;92:1172-80. 
26. Gopalan C, Rama Sastri B, Balasubramanian S. Nutritive value of Indian foods. 1971.

27. Pasricha S, Rebello LM. Some common Indian recipes and their nutritive value. National Institute of Nutrition, 1977.

28. The Food Monitoring Group. International collaborative project to compare and track the nutritional composition of fast foods. BMC Public Health 2012;12:559.

29. Dunford E, Webster J, Metzler AB, et al. International collaborative project to compare and monitor the nutritional composition of processed foods. Eur J Prev Cardiol 2012;19:1326-32.

30. CDC. Sodium reduction toolkit: a global opportunity to reduce population-level sodium intake, 2013.

31. PAHO. Policy Statement: preventing cardiovascular disease in the Americas by reducing dietary salt intake population-wide, 2010 .

32. Mohan S, Prabhakaran D, Krishnan A. Promoting populationwide salt reduction in the South-East Asia region: current status and future directions. Regional Health Forum, 2013.

33. He F, MacGregor G. A comprehensive review on salt and health and current experience of worldwide salt reduction programmes. J Hum Hypertens 2008;23:363-84.
34. Mohan V, Venkatraman JV, Pradeepa R. Epidemiology of cardiovascular disease in type 2 diabetes: the Indian scenario. J Diabetes Sci Technol 2010;4:158-70.

35. Shankar B, Brambila-Macias J, Traill B, et al. An evaluation of the UK Food Standards Agency's salt campaign. Health Econ 2013;22:243-50.

36. He FJ, Pombo-Rodrigues S, MacGregor GA. Salt reduction in England from 2003 to 2011: its relationship to blood pressure, stroke and ischaemic heart disease mortality. BMJ Open 2014;4:e004549.

37. Laatikainen T, Pietinen P, Valsta L, et al. Sodium in the Finnish diet: 20-year trends in urinary sodium excretion among the adult population. Eur J Clin Nutr 2006:60:965-70.

38. Hofman KJ, Tollman SM. Population health in South Africa: a view from the salt mines. Lancet Glob Health 2013;1:e66-7.

39. Gopalan C, Rama Sastri BV, Balasubramanian SC. Nutritive value of Indian foods. National Institute of Nutrition, 1989.

40. InterASIA Collaborative Group. Cardiovascular risk factor levels in urban and rural Thailand-The International Collaborative Study of Cardiovascular Disease in Asia (InterASIA). Eur J Cardiovasc Prev Rehabil 2003;10:249-57. 